Jurnal Pemberdayaan: Publikasi Hasil Pengabdian kepada Masyarakat

Vol. 2, No. 3, Desember 2018, Hal. 535-542

ISSN: 2088 4559; e-ISSN: XXXX-XXXX

DOI:

\title{
PEMBERDAYAAN MASYARAKAT DALAM MENINGKATKAN KUALITAS LINGKUNGAN SOSRODIPURAN
}

\author{
Asep Rustiawan ${ }^{1}$, Ma'ruf Fawwaz ${ }^{2}$, Tiara Erlinda Fatimah ${ }^{3}$ \\ 1,2,3 Universitas Ahmad Dahlan, Jalan Kapas, No 9, Semaki Yogyakarta 55166 \\ Email: asep.rustiawan@ikm.uad.ac.id
}

\begin{abstract}
ABSTRAK
Dusun Sosrodipuran Kelurahan Sosromenduran Kota Yogyakarta memiliki permasalahan kualitas lingkungan yaitu perumahan padat, halaman sempit, sampah dan lokasi endemik DBD. Kuliah Kerja Nyata UAD menggelar program untuk meningkatkan kualitas lingkungan dengan tujuan agar masyarakat lebih menyadari pentingnya peran lingkungan untuk kehidupan di sekitar wilayah Sosrodipuran. Warga masyarakat diharapkan dapat memanfaatkan lahan yang minim untuk melakukan berbagai hal, contohnya pemanfaatan tanaman Hidroponik. Disamping itu menumbuhkan kesadaran pada masyarakat untuk lebih peduli terhadap kebersihan lingkungan sekitar serta mengetahui cara untuk pengendalian jentik nyamuk. Metode yang digunakan yaitu praktek dan pendampingan untuk menanam tanaman Hidroponik, sosialisasi dan pembagian bubuk ABATE dan aksi pungut sampah. Hasil dan manfaat dari kegiatan ini adalah: 1) masyarakat dapat mengetahui bagaimana cara memanfaatkan lahan yang minim menjadi lebih bermanfaat, 2) mengetahui bagaimana cara membuat dan merawat tanaman hidroponik, 3) mengetahui cara pengendalian jentik nyamuk, 4) menumbuhkan kesadaran pada masyarakat untuk lebih peduli terhadap kebersihan lingkungan sekitar.
\end{abstract}

Kata kunci: pemberdayaan, dusun sosrodipuran, kesehatan lingkungan

\begin{abstract}
Sosrodipuran Hamlet, Sosromenduran Village, Yogyakarta City has environmental quality problems, namely dense housing, narrow yard, garbage and endemic DHF locations. The KKN UAD held a program to improve the quality of the environment in order for the community to be more aware of the importance of the role of the environment for life around the Sosrodipuran region. Community members are expected to be able to use land that is minimal to do various things, for example the use of hydroponic plants. Besides that, it raises awareness in the community to be more concerned about the cleanliness of the surrounding environment and know how to control mosquito larvae. The method used is practice and assistance to plant hydroponics, socialization and distribution of ABATE powder and garbage collection. The results and benefits of this activity are: 1) the community can find out how to use land that is minimal to be more useful, 2) know how to make and maintain hydroponic plants, 3) know how to control mosquito larvae, 4) raise awareness in the community for more care about the cleanliness of the surrounding environment.
\end{abstract}

Keywords: empowerment, sosrodipuran hamlet, environmental health 


\section{PENDAHULUAN}

Sosrodipuran merupakan salah satu dusun yang terletak di Kelurahan Sosromenduran, Kecamatan Gedongtengen, Yogyakarta. Batas wilayah dusun Sosrodipuran adalah sebagai berikut : 1) Wilayah Barat berbatasan dengan Kelurahan Pringgokusuman dan kelurahan Bumijo Kecamatan Jetis, mengikuti Jl. Jogonegaran, Jl. Yos. Sudarso, Jl. Jlagran dan Tentara Pelajar, 2) Wilayah Timur berbatasan dengan Kelurahan Suryatmajan Kec. Danurejan Kelurahan Gowongan Kec. Danuredjan mengikuti Jl. P Mangkubumi dan Jl. Malioboro, 3) Wilayah Selatan berbatasan dengan Kelurahan Ngupasan Kec. Gondomanan mengikuti Jl. Pajeksan, 4) Wilayah Utara berbatasan dengan Bumijo dan Kelurahan Gowongan Kec. Jetis mengikuti Jl. Suryonegaran, Jl. Bumijo, Jl. Gowongan Kidul.

Kelurahan Sosromenduran merupakan wilayah perkotaan di Yogyakarta yang lokasinya bersebelahan dengan jalan utama Malioboro. Sebagaimana ciri lokasi perkotaan lainnya, warga Sosromenduran tinggal di areal perumahan yang padat. Halaman rumah relatif sempit yang dihubungkan dengan gang sempit pula. Kebersihan lingkungan masih kurang terjaga dengan sampah yang berserakan di sudut-dsudut bangunan. Demikian pula saluran pembuangan/drainase yang di beberapa titik nampak tergenang. Kondisi lingungan seperti ini sangat sesuai untuk perkembangan jentik nyamuk. Tidak heran bila lokasi ini termasuk ke dalam wilayah endemik penyakit Demam Berdarah Dengue (DBD). Pada tahun 2016 yang lalu telah dilaporkan bahwa jumlah kasus DBD di wilayah kota Yogyakarta mencapai 1706 kasus dengan jumlah kematian sebanyak 13 orang (https://ugm.ac.id/id/berita/132062017.kasus.dbd.di.yogyakarta mencapai 53 kasus). Berdasarkan gambaran kualitas lingkungan tersebut, maka KKN kali ini diarahkan kepada peningkatan kualitas lingkungan melalui pemberdayaan masyarakat.

Pemberdayaan masyarakat dapat diartikan sebagai suatu upaya untuk memulihkan atau meningkatkan keberdayaan suatu komunitas agar mampu berbuat sesuai dengan harkat dan martabat mereka dalam melaksanakan hak-hak dan tanggung jawab mereka sebagai komunitas manusia dan warga negara (Harahap, 2012: 78). Adapun yang menjadi tujuan yang ingin dicapai dari pemberdayaan adalah untuk membentuk individu dan masyarakat menjadi mandiri. Kemandirian tersebut meliputi kemandirian berpikir, bertindak dan mengendalikan apa yang mereka lakukan. Pemberdayaan Masyarakat dan Desa/Kelurahan adalah upaya untuk mewujudkan kemampuan dan kemandirian masyarakat desa dan kelurahan yang meliputi aspek ekonomi, sosial budaya, politik dan lingkungan hidup melalui 
penguatan pemerintahan desa dan kelurahan, lembaga kemasyarakatan dan upaya dalam penguatan kapasitas masyarakat (Permendagri, 2007).

Banyak hal yang dapat dilakukan dalam rangka pemberdayaan masyarakat, salah satu yang dapat dilakukan adalah dengan cara meningkatkan derajat kesehatan lingkungan. Kualitas lingkungan baik diartikan sebagai keadaan lingkungan yang dapat memberikan daya dukung optimal bagi ke langsungan hidup manusia pada suatu wilayah. Kualitas lingkungan yang baik dicirikan antara lain dari suasana yang membuat orang merasa betah atau kerasan tinggal di tempatnya sendiri. Berbagai keperluan hidup terpenuhi dari kebutuhan dasar atau primer, meliputi makan, minum, perumahan, sampai kebutuhan rohani atau spiritual meliputi pendidikan, rasa aman, dan sarana ibadah.

Kegiatan untuk meningkatkan kualitas lingkungan bertujuan agar masyarakat lebih menyadari pentingnya peran lingkungan untuk kehidupan di sekitar wilayah Sosrodipuran. Warga masyarakat diharapkan dapat memanfaatkan lahan yang minim untuk melakukan berbagai hal, contohnya pemanfaatan tanaman Hidroponik. Disamping itu menumbuhkan kesadaran pada masyarakat untuk lebih peduli terhadap kebersihan lingkungan sekitar serta mengetahui cara untuk pengendalian jentik nyamuk.

\section{METODE PELAKSANAAN}

Pemberdayaan masyarakat untuk meningkatkan kualitas lingkungan Dusun Sosrodipuran dilakukan dengan metode praktek melalui program pendampingan pemanfaatan lahan minim untuk penanaman Hidroponik, sosialisasi dan pembagian bubuk ABATE serta aksi pungut sampah yang dilakukan secara berkala setiap 15 hari sekali. Rincian metode, kegiatan, JKEM, dan jumlah mahasiswa yang terlibat dapat dilihat pada Tabel 1 berikut ini. 
Tabel 1. Metode, Kegiatan, JKEM dan Jumah Mahasiswa yang Terlibat

\begin{tabular}{|c|c|c|c|c|}
\hline No & Metode & Kegiatan & JKEM & $\begin{array}{c}\text { Jumlah } \\
\text { mahasiswa } \\
\text { yang terlibat }\end{array}$ \\
\hline 1 & $\begin{array}{l}\text { Praktek pemanfaatan } \\
\text { lahan yang minim untuk } \\
\text { penanaman dan perawatan } \\
\text { tanaman Hidroponik }\end{array}$ & $\begin{array}{l}\text { Menyelenggarakan pemanfaatan } \\
\text { lahan yang minim untuk } \\
\text { penanaman dan perawatan } \\
\text { tanaman Hidroponik di Dusun } \\
\text { Sosrodipuran }\end{array}$ & $8 \times 50$ & 9 orang \\
\hline \multirow[t]{3}{*}{2} & \multirow[t]{3}{*}{$\begin{array}{l}\text { Praktek penyelenggaraan } \\
\text { Sosialisasi dan Pembagian } \\
\text { ABATE }\end{array}$} & $\begin{array}{l}\text { Memberikan sosialisasi tentang } \\
\text { ABATE kepada warga Dusun } \\
\text { Sosrodipuran }\end{array}$ & $1 \times 100^{\prime}$ & 9 orang \\
\hline & & Pemeriksaan Bak Air & $1 \times 100^{\prime}$ & 9 orang \\
\hline & & Pembagian Bubuk ABATE & $1 \times 100^{\prime}$ & 9 orang \\
\hline 3 & $\begin{array}{l}\text { Praktek penyelenggaraan } \\
\text { Aksi Pungut Sampah }\end{array}$ & $\begin{array}{l}\text { Melaksanakan aksi pungut } \\
\text { sampah bersama anak-anak di } \\
\text { sekitar Masjid Abdurrahman }\end{array}$ & $4 \times 100$ & 9 orang \\
\hline \multicolumn{3}{|c|}{ Total JKEM } & $1100^{\prime}$ & \\
\hline
\end{tabular}

\section{HASIL, PEMBAHASAN DAN MANFAAT}

\section{1). Profil Kelurahan}

Kelurahan Sosromenduran terbagi ke dalam 54 RT dan 14 RW, memiliki jumlah penduduk sebanyak 7655 jiwa yang terdiri dari 3737 laki-laki dan 3918 perempuan. Mata pencaharian utama adalah wiraswastawan/pekeja swasta dengan jumlah $87 \%$. Tingkat pendidikan rata-rata lulus SMA/sederajat dengan jumlah $34 \%$, dan tingkat perguruan tinggi sebanyak 19\%. Sebagian besar warga beragama islam.

Sarana prasarana kesehatan terdapat sebuah puskesmas, 14 UKBM dan 3 buah poliklinik. Untuk bidang pendidikan, terdapat 14 gedung PAUD, 5 gedung sekolah TK, 3 gedung sekolah SD, 4 gedung sekolah SLTP dan 2 gedung sekolah SMU. Untuk sarana ibadah terdapat 12 masjid, 4 gedung musholla dan 3 gedung gereja. Disamping itu terdapat 10 sarana olah raga, 5 sarana kesenian dan 7 balai pertemuan.

\section{2). Gambaran Pelaksanaan Kegiatan}

Masing-masing kegiatan dilaksanakan pada tanggal yang berbeda. Pertama adalah melaksanakan kegiatan penanaman hidroponik bersama warga di sekitar Masjid Abdurrahman, kemudian melaksankan sosialisasi ABATE, pemeriksaan bak air, serta pembagian bubuk ABATE kepada warga di sekitar masjid Abdurrahman. Kegiatan selanjutnya adalah aksi Pungut Sampah bersama anak-anak yang dilakukan setiap 15 kali 
sehari di sekitar wilayah Masjid Abdurrahman. Rincian dari kegiatan tersebut dapat dijelaskan sebagai berikut:

a. Pemanfaatan tanaman Hidroponik

Hidroponik juga dikenal sebagai soil-less culture atau budidaya tanaman tanpa tanah. Hidroponik adalah budidaya tanaman yang memanfaatkan air dan tanpa menggunakan media tanah (Roidah, 214). Kegiatan tersebut dilaksanakan pada tanggal 11 November 2018. Persiapan untuk melaksanakan kegiatan ini dimulai 20 oktober - 10 november. Persiapan yang dilakukan seperti mempersiapkan alat dan bahan yang diperlukan seperti, bibit tanaman Hidroponik, ember, nutrisi, hidroponik set, dan lain-lain.

Kegiatan ini diselenggarakan di pos kamling RW 06 di pagi hari. Warga RW 06 ikut berpartisipasi dalam kegiatan ini sebanyak 17 orang. Hal yang pertama dilakukan adalah memberikan penjelasan terkait tanaman Hidroponik, kemudian dilanjutkan dengan melakukan perakitan hidroponik set, pemasangan hidroponik set serta penanaman bibit.

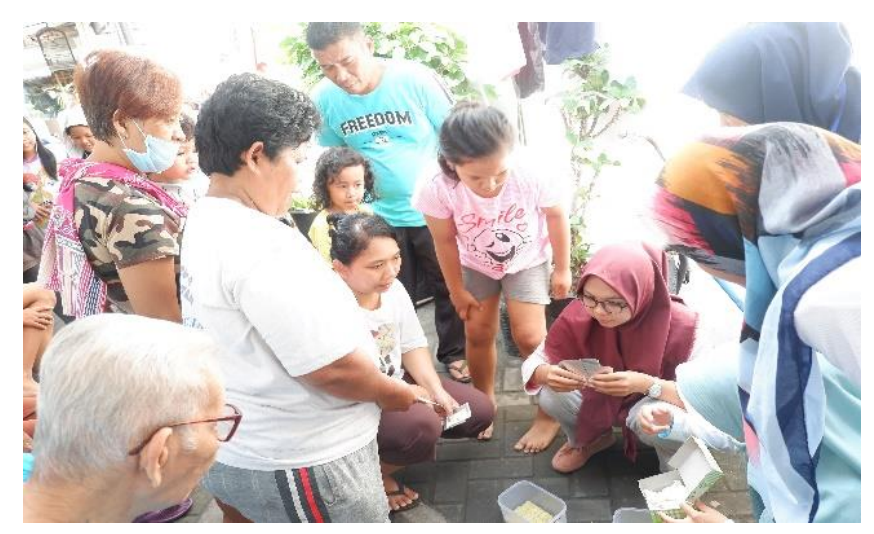

Gambar 1. Pemberian teori tentang hidroponik

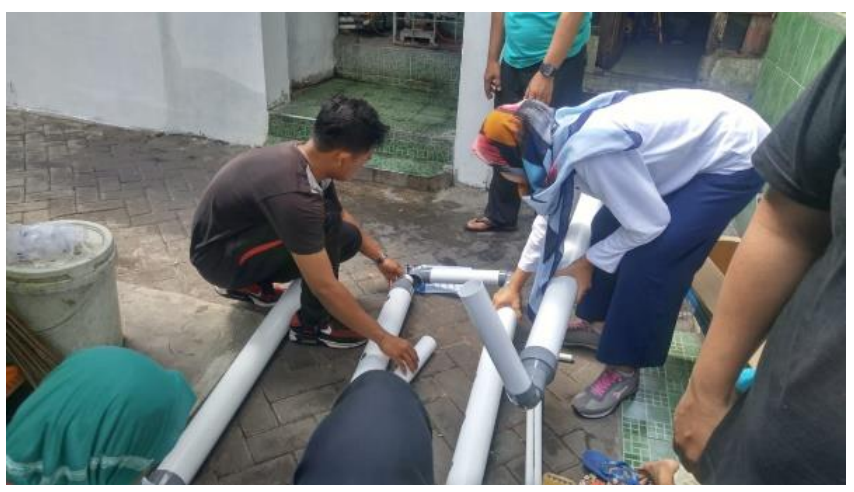

Gambar 2. Perakitan Pemasangan hidroponik set 


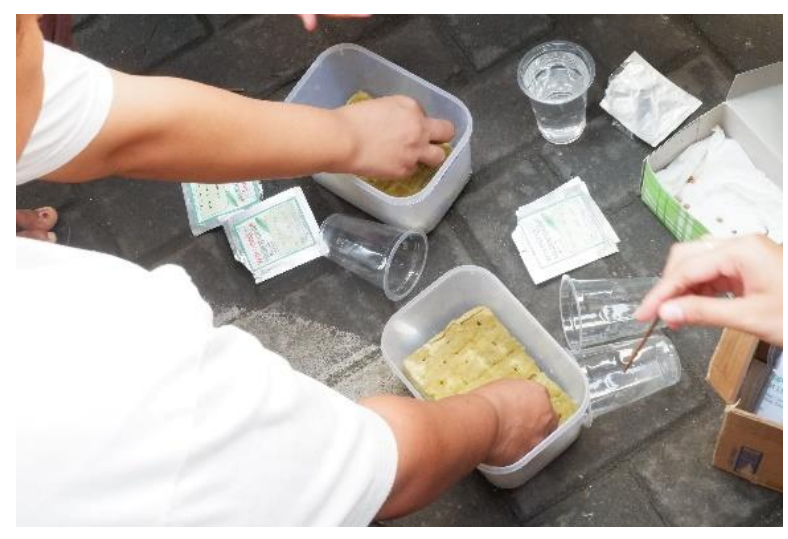

Gambar 3. Praktik bersama menanam bibit

b. Penyelenggaraan sosialisasi dan pembagian ABATE

Kegiatan ini dilaksanakan bertahap yaitu pada tanggal 10 Desember 2018 berupa sosialisasi ABATE dan pemeriksaan bak air, selanjutnya pada tanggal 14 Desember 2018 dilakukan pembagian bubuk ABATE kepada warga di wilayah Masjid Abdurrahman. Kegiatan ini diharapkan dapat menurunkan angka jentik di sekitar wilayah Masjid Abdurrahman.

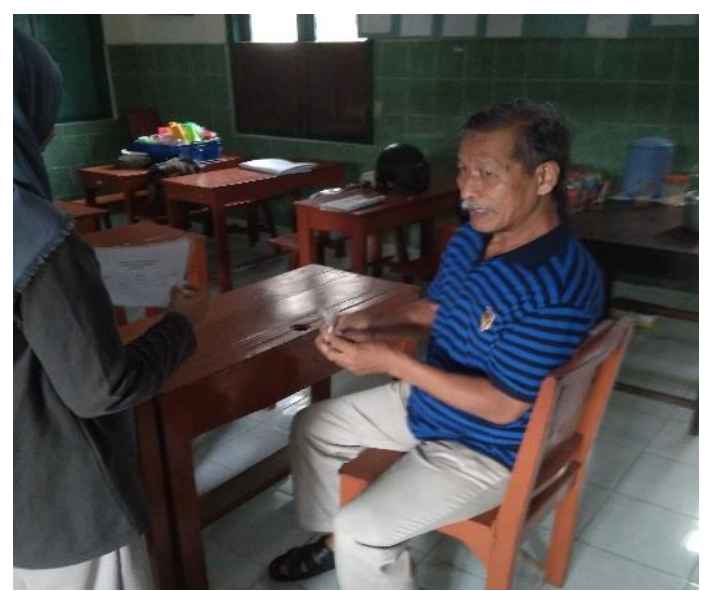

Gambar 4. Pembagian bubuk ABATE

c. Penyelenggaraan Aksi Pungut Sampah

Kegiatan ini dilaksanakan bertahap yaitu pada tanggal 20 Oktober 2018, 3 November 2018, 9 Desember 2018, dan 13 Desember 2018. Kegiatan ini dilaksanakan di wilayah sekitar Masjid Abd Rahman. Kegiatan ini bertujuan untuk meningkatkan kesadaran masyarakat agar lebih memperhatikan kebersihan lingkungan di sekitarnya guna terciptanya lingkungan yang bersih. 


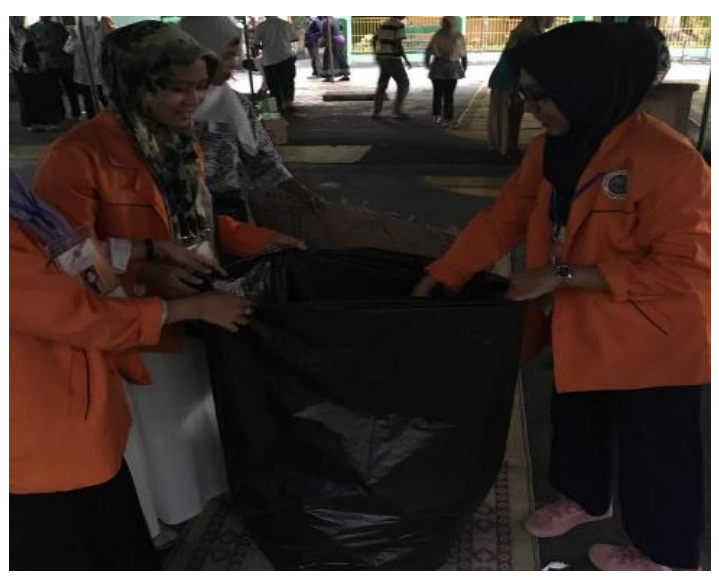

Gambar 5. Aksi pungut sampah

Berdasarkan rincian kegiatan tersebut di atas, manfaat yang diperoleh masyarakat adalah :

a. Masyarakat dapat mengetahui bagaimana cara memanfaatkan lahan yang minim menjadi lebih bermanfaat,

b. Masyarakat dapat mengetahui bagaimana cara membuat dan merawat tanaman hidroponik,

c. Masyarakat dapat mengetahui bagaimana cara pengendalikan jentik nyamuk dengan ABATE,

d. Tumbuhnya kesadaran pada masyarakat untuk lebih peduli terhadap kebersihan lingkungan sekitar.

\section{KESIMPULAN}

Kesimpulan yang dapat ditarik dari penjelasan di atas adalah sebagai berikut.

1. Masyarakat dapat memanfaatkan lahan yang minim menjadi lebih produktif.

2. Tumbuhnya kesadaran pada masyarakat untuk lebih peduli terhadap kebersihan lingkungan sekitar.

3. Masyarakat mengetahui cara pengendalian jentik nyamuk dengan menggunakan ABATE.

\section{DAFTAR PUSTAKA}

Harahap, Erni Febrina. 2012. Pemberdayaan Masyarakat dalam Bidang Ekonomi untuk Mewujudkan Ekonomi Nasional yang Tanggung dan Mandiri. Jurnal Manajemen dan Kewirausahaan. Vol.3 (2). Hal. 78-96.

https://ugm.ac.id/id/berita/13206-2017.kasus.dbd.di.yogyakarta.mencapai.53.kasus. Diakses pada: 13 Januari 2018. 
Permendagri RI Nomor 7 Tahhun 2007 tentang Kader Pemberdayaan Masyarakat, Bandung : Fokus Media.

Roidah, Ida Syamsu, 2014. Pemanfaatan Lahan Dengan Menggunakan Sistem Hidroponik. Jurnal Universitas Tulungagung BONOROWO. Vol. 1. No.2. 